Faculdade de Ciências Econômicas UFRGS

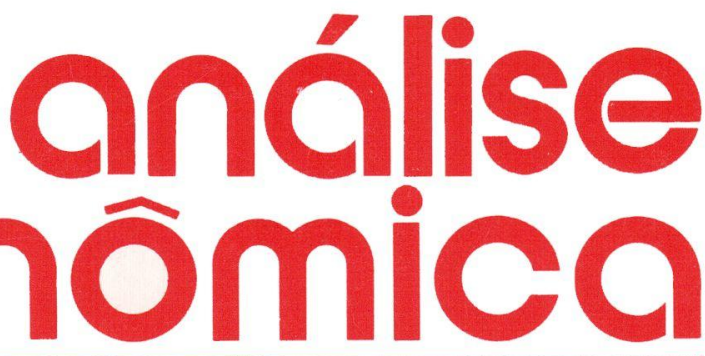

- COMÉRCIO INTERNACIONAL: UMA AGENDA DE PESQUISAS Carlos Alberto Primo Braga

- INFLACÃO E REFORMA MONETÁRIA: KEYNES E MISES Francisco Anuatti

- A ECONOMIA COMO CIÉNCIA Eleutério F.S. Prado

- REAVAlIAÇ̃̃o das PRIVATIZAÇÕES EM PAÍSES EUROPEUS

Márcio Wohlers de Almeida

- INTEGRAÇÃo BRASIL-ARGENTINA E A PRODUÇÃO DE GRÃOS José Eduardo Gutiérrez Perez Walter José Stülp

- SUBSTITUIÇÃO DE COLONOS POR TRABALHADORES ASSALARIADOS

Carlos José Caetano Bacha

- EQUILÍBRIO DISTRIBUTIVO EM MODELOS KALDORIANOS AMPLIADOS Joanílio Rodolpho Teixeira Jorge Thompson Araújo

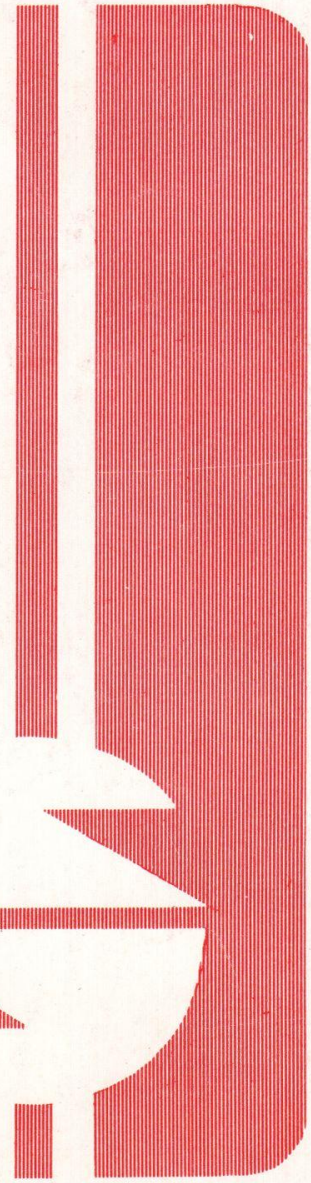


UNIVERSIDADE FEDERAL DO RIO GRANDE DO SUL.

Reitor: Prof. Tuiskon Dick

FACULDADE DE CIËNCIAS ECONÔMICAS

Diretor. Prof. Walter Meucci Nique

CENTRO DE ESTUDOS E PESQUISAS ECONÔMICAS

Diretor. Prof. Reinaldo Ignacio Adams

DEPARTAMENTO DE CIÊNCIAS ECONÔMICAS

Chefe: Prof. Pedro Cezar Dutra Fonseca

CURSO DE PÓS-GRADUAÇĀO EM ECONOMIA

Coordenador. Prof. Roberto Camps Moraes

CURSO DE PÓS-GRADUAÇĀO EM ECONOMIA RURAL

Coordenador. Prot. Aray Miguel Feldens

CONSELHO EDITORIAL:

Achyles Barcelos da Costa, Aray Miguel Feldens, Atos Freitas Grawunder, Carlos Augusto Crusius, Emani Hickmann, João Rogério Sanson, Juvir Luiz Mattuella, Maria Imilda da Costa e Silva; Nali de Jesus de Souza, Nuno Renan Lopes de Figueiredo Pinto, Ot́lia Beatriz Kroeff Carrion, Otto Guilherme Konzen, Paulo Alexandre Spohr, Pedro Cezar Dutra Fonseca, Reinaldo Ignacio Adams, Roberto Camps Moraes, Valter José Stülp, Yeda Rorato Crusius, Edgar Augusto Lanzer (UFSC) e Humberto Vendelino Richeter (UnB)

COMISSĀO EDITORIAL: Atos Freitas Grawunder, Pedro Cezar Dutra Fonseca, Reinaldo Ignacio Adams e Roberto Camps Moraes.

EDITOR: Nali de Jesus de Souza

SECRETARIA: Francisco Carlos Becco dos Santos, Maria Ivone de Mello (normalização), Vanete Ricacheski (revisão de textos), Wagner Nunes e Zélide Bregalda.

FUNDADOR: Prof. Antônio Carlos Santos Rosa

A Revista ANÁLISE ECONÔMICA publica dois números anuais nos meses de março e novembro. O preço da assinatura, para 1990, é de 7,0 BTNs (o número avulso custa 4 BTNs), a ser pago através de cheque nominal em nome da "Faculdade de Ciências Econômicas/ UFRGS". Aceita-se permuta com revistas congêneres. Aceitam-se, também, livros para elaboração de resenhas ou recensōes.

Toda correspondência, material para publicação, assinaturas e permutas devem ser dirigidos ao seguinte destinatário:

PROF. NALI DE JESUS DE SOUZA

Revista Análise Econômica

Av. João Pessoa, 52 - sala 28

90.040 - PORTO ALEGRE (RS) - BRASIL

Telefone: 25-5844 ramal 34 


\section{UMA ABORDAGEM ALTERNATIVA NA INTERPRETAÇÃO DA SUBSTITUIÇÃO DOS COLONOS PELOS TRABALHADORES ASSALARIADOS}

Carlos José Caetano Bacha 2

\section{1 - INTRODUÇÃO}

Existem evidências, que serảo mostradas posteriormente, do uso de trabalhadores diaristas na agricultura paulista e fluminense nas décadas de 40 e 50. Assim, podemos afirmar que a transformaçāo dos colonos em trabalhadores assalariados permanentes e temporários ${ }^{3}$ já existia antes da década de 60 . Porém, a partir de 1964, acelerou-se essa transformação, praticamente extinguindo a categoria de colonos na década de 70.

STOLCKE (1986, p. 182 e 183) analisando a agricultura paulista,

1 Desejo expressar meus agradecimentos às crticas dos Profs. Oriowaldo Queda e Rodolfo Hoftmann, ressaltando que as idéias e possiveis erros existentes neste artigo são de toda a responsabilidade do autor.

2 Professor da ESALQ-USP. Trabalho apresentado no XVII Encontro Nacional de Economia da ANPEC, realizado em Fortaleza, Ceará, em dezembro de 1989.

3 Neste texto, trabalhadores temporários serão também chamados de volantes, e se constituem de pequenos proprietários não tecnificado (que se assalariam fora de sua pequena produção para complementarem suas rendas) e de bóias-frias. Esses últimos são distintos em alguns pontos, constituindo três grupos, como ressaltado por SILVA (1981). Segundo SILVA e RODRIGUES (1982, p. 61) o boia-fria é um "trabalhador rural, residente fora da propriedade agricola, geralmente na periferia das vilas ou cidades, registrado ou não, recebendo por empreitada, tarefa ou por dia, aliciado ou não por turmeiro e que, geralmente, se locomove todos os dias para o local de trabalho, quase sempre em caminhóes".

\begin{tabular}{|l|l|l|l|l|}
\hline ANÁLISE ECONÔMICA & ANO 7 & № 12 & NOVEMBRO/89 & p.121-138 \\
\hline
\end{tabular}


argumenta que alguns analistas, inicialmente, atribulam este fenômeno da substituição da colonos por trabalhadores assalariados ao Estatuto do Trabalhador Rural (implementado em 1963), que conduzia os fazendeiros a dispensarem o colonos e contratarem mão-de-obra sazonal como forma de burlar as leis trabalhistas. Outros estudos posteriores sobre essa transformação omitiram, ou consideraram como fator secundário, o Estatuto do Trabalhador Rural, interpretando a expansão do trabalho assalariado eventual como conseqüência e sintoma do avanço do capitalismo na agricultura. Outro aspecto que constatamos na literatura sobre a transformação do colono em trabalhadores assalariados é o domínio da análise com instrumental marxista.

Este artigo tem como objetivo mostrar que o instrumental da teoria da firma em concorrência também é adequado para explicar a aceleração da transformação dos colonos em assalariados a partir de 1964. Nossa hipótese é que os vários elementos citados pela literatura existente (que revisaremos a seguir) afetaram os custos de utilização de formas alternativas de mão-de-obra, sendo que os fazendeiros (aqui considerados como firmas) procuraram utilizar as formas de mão-deobra que minimizam seus custos, pois, assim, maximizam seus lucros.

Três pontos devem ser explicitados desde já. Dividimos o período da transformação do colono em assalariados, em antes de 1964 e a partir desse ano, procurando explicar os fatores que aceleraram essa transformação no segundo período.

Em segundo lugar, propomos uma interpretação com o uso do instrumental neoclássico do processo em estudo, mas não nos dedicamos a julgar se ela (nossa interpretaçāo) é mais, ou menos, adequada que as abordagens já existentes que utilizam o instrumental marxista. A diferença principal entre as duas abordagens é que a neoclássica tem uma visāo microscópica e subjetiva da economia, permitindo uma análise baseada na tomada de decisão do fazendeiro, dadas certas condições. As abordagens com instrumental marxista têm uma visão macroscópica e objetiva da economia.

O terceiro ponto a ressaltar é que quando nos referimos ao instrumental da teoria da firma em concorrência não fazemos uso aprofundado da teoria da produção, dos custos e dos rendimentos, mas, apenas, utilizamos sua conclusão de que a firma maximiza os lucros minizando os seus custos, dando atenção especial ao custo representado pelos gastos com mão-de-obra.

No item 2, apresentamos uma revisão bibliográfica sobre o tema, mostrando a evolução das abordagens e dos fatores que foram consi- 
derados como determinantes da transformação. Em seguida, colocamos a interpretação neoclássica sobre o processo em estudo (item 3).

\section{2 - REVISÃo DA LITERATURA SOBRE O PROCESSO DE TRANSFORMAÇÃO DA MÃO-DE-OBRA NA AGICULTURA BRASILEIRA}

As primeiras análises sobre a transformaçāo dos colonos em trabalhadores assalariados colocaram o Estatuto do Trabalhador Rural (ETR) como a causa principal de tal transformação. Isto deveu-se ao fato do ETR ter sido percebido pelos agentes econômicos, que presenciaram essa transformaçāo na metade da década de 60 , como o causador imediato da expulsão dos colonos.

No trabalho da COOPERCOTIA (1968), constatamos que era uma opinião unânime de patrōes, agrônomos e até de alguns sindicalistas rurais em São Paulo, em 1968, a importância do Estatuto do Trabalhdor Rural como uma das causas da ampliação de volantes na agricultura brasileira.

PAIVA, SCHATTAN e FREITAS (1976, p.218), em trabalho concluído em 1973, argumentam que a legislação trabalhista rural tem sido garantida ao trabalhador rural de forma satisfatória, tendo em vista a extensão da área e dos problemas a serem fiscalizados, e aplicada, às vezes, com excessivo rigor em algumas áreas de agricultura mais organizada e permanente. ${ }^{4}$ Essa legislação foi a responsável pela substituição dos antigos colonos e moradores por trabalhadores volantes intermediados pelos empreiteiros, pois

... "Os proprietários agrícolas (...) procuram defender-se dos excessos de rigor da lei usando medidas cujos controles não foram previstos no quadro geral da legislação, como é o de simıplesmente despedir os empregados seguindo as exigências da lei e contratá-los como diaristas (chamados de "volantes") e através de "empreiteiros" que tomam a si os encargos trabalhistas do empregador rural, mas que podem mais facilmente burlar as exigências legais."

${ }^{4}$ É importante ressaltar que os autores citados não fundamentam essa colocaçăo com dados emplricos. 
Trabalhos posteriores aos acima comentados procuraram levantar outras causas estruturais que já se desenvolviam, além da ciscunstancial representada pelo ETR, para a transformação dos colonos em assalariados, havendo estudos que colocaram essa legislação como um ratificador do processo e não o seu determinante.

GASQUES et alii $(1977$, p.84) afirmam que em São Paulo a mãode-obra volante é um produto das transformações ocorridas na estrutura da produção agrícola e da instituição da legislação social no meio rural em 1963 e 1964. Segundo esses autores:

“No Estado de São Paulo a introdução de máquinas agrícolas de vários tipos, a aplicação de técnicas de produção mais modernas e a transformaçāo de parte das terras de lavoura em pastagem, foram algumas práticas bastante usadas no âmbito da produção agrícola. Deste modo, a diminuição da procura de trabalho, em termos relativos e absolutos, deve ter provocado um excesso relativo de mão-de-obra no meio rural. Parte dos serviços do fator trabalho passou a ser demandada somente em algumas épocas do ano, quando se intensifica as atividades agricolas, enquanto outra parte foi substituída por outros fatores da produção.

"O emprego de mão-de-obra temporária generalizou-se por todo o Estado de São Paulo. São os chamados volantes, trabaIhadores assalariados que moram nos arredores das cidades, mas oferecem seus servios para os trabalhos no campo.

$(\ldots)$

"E importante ressaltar que a mão-de-obra volante parece ser um produto não apenas de transformações ocorridas na estrutura da produção agrícola, mas também causada pela instituição da legislação social no meio ura! nos anos de 1963 e 1964. Nos anos de 1964 e 1966 é que se observaram as maiores taxas de crescimento de volantes no Estado de São Paulo."

CACCIAMALI e AGUIRRE (1984, p.86) não acreditam que a legislação trabalhista seja a responsável pelo surgimento do trabalho temporário. Argumentam que os responsáveis pelo surgimento do trabalho temporário são as disponibilidades de tecnologia e de mão-deobra. Essas autoras enfatizam o lado da ofertá de fatores de produção determinando o uso de mão-de-obra temporária. Para elas

... “... numa economia capitalista, o processo produtivo na 
agricultura, em sendo descontínua, pode implicar ou não utilização de assalariamento temporário em determinados "picos", por exemplo, plantio e colheita. Essa relação vai ocorrer à medida que: (i) não haja tecnologia disponivel e eccnomicamente rentấvel que conduza ao uso intensivo de máquinas, e (ii) exista força de trabalho disponível nesses períodos.

(...)

"A afirmação de que o surgimento de legislação espedifica regulamentando as relações de trabaiho no campo foi responsável pelo surgimento de assalariamento temporário é ao nosso ver inconsistente. Inúmeros estucios demonstram a existência dessa relação de trabalho no Brasil desde a década de 30 . Além disso, não é uma relação de trabalho típica de nosso pals ou somente de economias atrasadas. $O$ assalariamento temporário existiu no passado, nos países hoje industrializados, e continua existindo em países como por exemplo Estados Unidos e França, na época da colheita de frutas. Assim sendo, acreditamos que o papel da legislação foi apenas o de regular uma relação de trabalho existente, não de criá-la."

Sobre o tema aqui tratado, desenvolveram-se estudos com base no instrumental marxista, que entendem a substituição dos colonos por assalariados temporários como sendo devida ao processo de avanço do capitalismo na agricultura brasileira, criando as condições e incentivos ao uso dessa forma de mão-de-obra intermitente como meio de valorização do capital. Nesta literatura, que vem dominando o tema, destacamos os trabalhos de GONZALES e BASTOS (1979), D'INCAO E MELLO (1976), BRANT (1977) e de SILVA (1981).

Para GONZALES e BASTOS (1979), a substituição dos colonos, parceiros e trabalhadores assalariados permanentes por trabalhadores assalariados volantes é fruto do processo de valorização do capital que, condicionado pelo crescente aumento do volume de capital nas mãos dos empresários agrícolas e pela disponibilidade de um contingente de trabalhadores despojados dos meios de produção, levou a escolha de trabalhadores volantes ao invés das outras categorias como maneira de auferir maiores lucros. Para os autores, o Estatuto do Trabalhador Rural, os tipos de culturas e a mecanização são elementos colaterais na determinação do processo de avanço de emprego volante.

Para D’INCAO e MELLO (1976, p.116), a utilização de bóias-trias na regiāo da Alta Sorocabana de Presidente Prudente e Presidente 
Venceslau é explicada pelo comportamento empresarial na busca de sistemas de exploração da força de trabalho que impliquem menores custos. Por exemplo, a falta de capital para arcar com os salários levou as lavouras de amendoim e algodāo a serem conduzidas com arrendatários e parceiros, e nāo com colonos. A introduçāo da mecanização na agricultura (em decorrência da própria acumulação, dos financiamentos bancários e da elevação do preço da terra) elevou a produtividade do trabalho e diminuiu a quantidade de mão-de-obra necessária, tornando mais vantajoso o uso de assalariados, contratados na forma de diaristas, que permitia, assim, o não cumprimento do Estatuto do Trabalhador Rural. O uso de bóias-frias ocorre devido à existência de um excedente da força de trabalho nas cidades, oriunda do campo devido à substituição de culturas por pecuária e devido à própria mecanização, e por ser adequada ao uso intermitente. Isto tem permitido o seu uso, junto com máquinas, na renovação de pastagens ao invés de arrendatários; e na complementaçằo do trabalho de parceiros nas lavouras em que se mantém (além do caso já citado dos plantios de algodão e amendoim). Em suma, o bóia-fria é usado porque implica menores custos, sendo que o Estatuto do Trabalhador Rural permite a contratação dessa forma de assalariado sem o pagamento dos encargos trabalhistas.

BRANT (1977) analisando a região da Alta Sorocabana de Assis, concluiu que para haver o desenvolvimento da cafeicultura nas 4 primeiras décadas do presente século nessa área de relativa escassez populacional era necessário empregar mão-de-obra que ocupasse o tempo e área excedentes não dedicados à cafeicultura na geração de parte de sua sobrevivência. Foi por isso que se estabeleceu o colonato. Em suma, o colonato surgiu da ausência de um mercado de trabaIho e de alimentos na regiāo. Contudo, esses foram sendo constituidos a partir da década de $40 \mathrm{com}$ as transformaçōes nas empresas agropecuárias, que substituíam o café pela pecuária e por outras culturas temporárias menos exigentes em mão-de-obra. $\mathrm{O}$ excedente de mão-de-obra foi, entāo, liberado das fazendas e, em parte, empregouse nas áreas deixadas pelo café para a produção de bens de mercado inteiro. A aceleração da expulsão, a um ritmo superior ao do crescimento da pequena produção, permitiu a geração de um mercado de trabalho temporário (sustentado pela produção local de alimentos) que foi substituindo os colonos.

Segundo BRANT (1977, p.81), os fazendeiros da Alta Sorocabana de Assis culpam a legislação trabalhista pelo encarecimento da 
mão-de-obra e, conseqüentemente, por sua dispensa. $O$ autor encara tal argumentação como ideológica, pois o custo dos salários deve ser comparado com os preços dos produtos agrícolas e com os preços dos outros insumos e, na interpretação do autor, a expulsão de trabalhadores a partir de 1964 está ligada à política de erradicação de cafeeiros patrocinada pelo IBC; nos anos 1966-68 a expulsão está ligada à queda da receita agricola determinada pela política de contenção da inflação nos anos anteriores;'e depois de 1970, a expulsão liga-se a uma conjuntura de elevação dos preços agrícolas e a uma política governamental de incentivos à capitalização da agricultura que favorece a compra de insumos modernos.

Para SILVA (1981), o trabalho volante é fruto de um avanço incompleto na base técnica da agricultura (devido à insuficiência do capital em submeter as forças da natureza), que aumentou a sazonalidade no uso de mão-de-obra e tornou mais lucrativo a contratação de trabalhadores temporários num mercado de trabalho formado pelo excedente de mão-de-obra expulsa das propriedades agrícolas pelo próprio avanço das relaçōes capitalistas no campo. Diz SILVA (1981, p.119):

"...(É) mais correto afirmar que, além do assalariamento temporário ser um produto do desenvolvimento das forças capitalistas na agricultura (enquanto embriāo da formação proletariado rural) ele é, ao mesmo tempo, resultado da insuficiência e da fraqueza desse desenvolvimento: da insuficiência do capital em submeter as forças da natureza, do ponto de vista técnico; da fraqueza de generalizar essa subordinação, não apenas do ponto de vista formal, mas sobretudo de uma maneira real e ampla, revolucionando a produção agrícola em todas as suas fases."

Em seguida, o autor analisa a evolução e composição dos trabaIhadores rurais em São Paulo (onde houve o avanço das forças produtivas na agricultura), constatando que houve o aumento relativo do número de trabalhadores assalariados, especialmente dos não-residentes (e entre eles dos trabalhadores volantes). E sobre a importância do Estatuto do Trabalhador Rural, da erradicação de cafezais, da substituição de culturas na determinação do surgimento de trabalhdores volantes SILVA (1981, p.126) conclui:

"No sentido de que não podem ser confundidos como cau-, 
sa, mas apenas como fatores que aceleram, sāo catalisadores do aumento da participação relativa dos trabalhadores volantes no início da década dos sessenta, em especia!: a legislação trabalhista estendida ao meio rural; a erradicação dos cafezais e sua substituição pela pecuária e lavouras menos exigentes em mão-de-obra ou com elevada sazonalidade de trabaIho; e a tratorização, juntamente com outras técnicas modernas introduzidas nas lavouras. $\dot{E}$ impossível isolar o efeito de cada um deles porque justamente a intensidade do processo de conversão dos trabalhadores residentes em volantes se deveu à coincidência cronológica e geográfica desses fatores."

Em seguida, SILVA (1981, p. 127) apresenta algumas citações de autores que comentaram a utilizaçāo de trabalhadores assalariados temporários nas agriculturas paulista e fluminense no período do final do século XIX até a década de 50 , como estratégia de refutar a afirmação de que o Estatuto do Trabalhador Rural fosse a causa do aparecimento do volante.

Um comentário especial deve ser dado ao trabalho de STOLCKE (1986) sobre o processo de substituiçāo dos colonos por trabalhadores volantes. Embora essa autora utilize o instrumental analítico marxista, ela procura ressaltar as modificações nas relaçōes de trabalho a partir das lutas de classes, argumentando que a legislação trabalhista rüral teve um papel importante na substituição dos colonos por trabalhadores volantes.

O trabalho de STOLCKE (1986) analisa as transformaçōes das relações de produção nas fazendas cafeeiras paulistas como sendo determinadas, principalmente, pelo confronto entre o poder dos fazendeiros e os diferentes modos de resistência do trabalhador à exploração e à disciplina do trabalho.

A primeira experiência com o trabalho livre foi a parceria que, devıdo à exploração da dívida inicial e da sua manutenção e incremento, com o passar do tempo conduziu os parceiros a dedicarem-se menos ao cultivo do café, tornando baixa a produtividade dessa forma de trabalho. Com a imigração financiada pelo governo, a dívida inicial foi suprimida no sistema de colonato, e a produtividade pôde ser mantida a níveis satisfatórios pelo sistema de pagamento por tarefa (pagamento pelos tratos culturais de determinado número de pés de café) e por produção (pagamento por volume de colheita), além do trabalhador arcar com parte do custo de sua sobrevivência, cultivando uma lavoura 
de produtos de consumo próprio. Conflitos ocorreram no colonato, onde a resistência dos trabalhadores à taxa de reapropriação do trabalho excedente imposta pelos fazendeiros provocou reajustes na forma da exploração do trabalho, o que gerou novas formas de luta.

Em 1963, a introduçã de leis trabalhistas no campo, garantindo a estabilidade e a indenização por dispensa, limitou o direito de contratação e, logicamente, de domínio dos patrões sobre a mão-de-obra, o que os conduziu a substituir os colonos por volantes. Estes estavam vinculados aos turmeiros, de modo que desobrigavam os fazendeiros do compromisso de cumprir os direitos trabalhistas de estabilidade e indenização, pois não caracterizava, assim o vínculo contratual entre o trabalhador e o fazendeiro. Desse modo, o fazendeiro pôde retomar o controle sobre o processo de produção e, logicamente, sobre a apropriação do trabalho excedente a níveis similares ao passado.

STOLCKE (1986) ressalta que a aludida elevação dos custos de mão-de-obra, gerada pela nova legislação, obscurecia a relutância dos fazendeiros em perder parte de seu poder de exploração. 5

Todos os trabalhos analisados acima, não obstante marcos teóricos distintos, enfatizam que a substituição de colonos por assalariados temporários deveu-se à ocorrência de mudanças nas condições econômicas que tornaram viável e economicamente vantajosa tal substituição. Os trabalhos distinguem-se nos fatos e na ênfase que são as mudanças mais importantes no ambiente econćnnico. Os primeiros trabalhos que analisaram a substituição de colonos por assalariados temporários enfatizaram o Estatuto do Trabalhador Rural como seu determinante, e os trabalhos que vieram em seguida levantaram outras causas, como as mudanças na base técnica, a substituição de cultur ras, a erradicação de cafeeiros, a expansão da pecuária, entre outros fatores.

\footnotetext{
5 Quanto a outros fatores que têm sido considerados como determinantes da substituiçáo dos colonos por trabalhadores volantes, temos que STOLCKE (1986, p. 188 a 195) concluiu que - progresso tecnologico pouco avançou nas fazendas cafeeiras paulistas no final dos anos 50 e nos anos seguintes. A mesma autora concluiu que eram poucas as fazendas que cultivavam intensamente o café, suprimindo as culturas alimentares de subsistência ou tornando seu cultivo comercial, de modo a substituir os colonos por empreiteiros ou por trabalhadores assalariados (veja STOLCKE (1986, p. 195 a 200). Em seguida, STOLCKE (1986, p. 200 a 204) ressaltou que a erradicaçăo de cafeeiros teve um efeito consideråvel sobre o emprego no setor cafeeiro paulista.
} 


\section{3 - PROPOSTA DE INTERPRETAÇÃO SOBRE O PROCESSO DE MUDANÇA NO USO DE MÃO-DE-OBRA NA AGRICULTURA BRASILEIRA}

A nossa interpretação, como a de todos os trabalhos acima comentados, é que os fazendeiros na escolha da forma de uso de mãode-obra na agricultura brasileira pautaram-se em utilizar, entre as formas possíveis, a de menor custo, tal que maximizassem os seus lucros. Não obstante, acreditamos que tal procedimento e situação pode ser explicado com o auxílio da teoria da firma em concorrência, que maximiza os lucros minimizando os custos. A seguir mostramos as modificaçōes nos "ceteris paribus" que conduziram os fazendeiros (firmas) a alterarem as formas de mão-de-obra usadas na agricultura. Considerados os fatores mencionados na literatura revista no item anterior.

O uso do colonato na agricultura paulista ocorreu porque a falta de uma mão-de-obra ocupada em atividades marginais, a pouca circulação de moeda na economia e os elevados preços dos produtos de subsistência nas áreas cafeeiras tornaram o uso dessa forma de mãode-obra mais barato do que o uso de mão-de-obra assalariada. $\mathrm{Na}$ mesma época, na cafeicultura da Zona da Mata o uso de meeiros suplementados por trabalhadores volantes, ocupados em atividades marginais no norte do Estado, implicou menor custo do que o uso de colonos ou mão-de-obra assalariada, devido à menor produtividade da cafeicultura da Zona da Mata em relação à paulista.

Devemos ressaltar que o uso de mão-de-obra assalariada diarista não um fenômeno recente na agricultura brasileira. Țal situação foi observada em alguns Estados antes da década de 60. SILVA e RODRIGUES (1982, p.62) comentam que, em trabalho realizado sobre a regiāo canavieira de Piracicaba por Bombo e Bruneli, evidenciou-se a presença de volantes em 1945; e, como ressaltamos no item anterior, o trabalho de SILVA (1981, p.127) apresenta algumas citações de autores que comentaram a utilizaçāo de trabalhadores temporários nas agriculturas paulista e fluminense no periodo do final do século XIX até a década de 50. Assim, procuramos explicar porque se acelerou o processo de transformação de colonos em trabalhadores assalariados volantes e permanentes.

Nossa interpretação é que o processo de transformação dos colonos em trabalhadores assalariados foi acelerado na década de 60 
porque fenômenos institucionais (representados pela legislação trabaIhista rural), a mudança de culturas (de café para pecuária) e os avanços tecnológicos elevaram, ao nível de fazendas (firmas), o custo de utilização de colonos em relação a uma combinação de um número mínimo de trabalhadores assalariados permanentes, suplementados pelos trabalhadores assalariados e temporários (esse é o lado da demanda por formas de mão-de-obra). ${ }^{6}$ Esses últimos puderam ser contratados entre a massa de trabalhadores expulsos das propriedades (esse é o lado da oferta de formas de mão-de-obra), devido ao medo gerado pelo Estatuto do Trabalhador Rural), à modernização e às erradicações de cafeeiros em São Paulo, Paraná, Minas Gerais e Espĺrito Santo que foram substituldos por atividades menos exigentes em mãode-obra. Podendo realizar suas atividades com uma combinação de trabalhadores assalariados a um custo menor do que utilizando colonos, os fazendeiros substituíram estes por aqueles, pois, assim, minimizavam custos e, desse modo, procuravam maximizar seus lucros.

Não é nossa preocupação ordenar os fatores acima quanto à sua importância na transformação de colonos em assalariados, mas sim mostrar como atuaram nessa transformação.

Concordamos com os autores que alegam que o ETR surgiu para sancionar um processo já existente. ${ }^{7}$ Mas compartilhamos da opiniāo de MOURA (1980) de que essa legislação, uma vez implementada, acelerou a transformação dos colonos em assalariados nas regióes onde já ocorria esse processo, bem como gerou-os em outras regiōes. Isto porque, a substituição dos colonos por trabalhadores assalariados antes de 1963 não ocorria em toda a agricultura brasileira, mas apenas em algumas regiōes. Uma vez que o ETR foi instituido em toda a agricultura, ele ratificou o processo naquelas regiões, acelerando-0, mas também o criando em outras partes da agricultura. ${ }^{8}$

${ }^{6}$ A discussão sobre a suplementação, e não complementação ou substituição, entre trabalhadores assalariados permanentes e temporários pode ser vista em BACHA (1988, P. 242 a 245).

7 Entre esses autores está CACCIAMALI e AGUIRRE (1984).

8 Nossa abordagem sendo microscópica e subjetiva năo permite incorporar uma análise dos determinantes do surgimento do ETR em 1963. Para nossa preocupação, uma vez instituída essa legislação, alterou-se o "Ceteris Paribus" dos fazendeiros, levando-os a ratificar e acelerar o processo de transformaçăo dos colonos em assalariados nas regióos onde já ocorria, mas criando-o em outras regióes.

Acreditamos que o ETR surgiu em 1963 a partir das pressőes dos sindicatos de trabalhado- 
Para entendermos como a extensão da legislação trabalhista ao campo, representada inicialmente pelo Estatuto do Trabalhador Rural (ETR), acelerou o uso de mão-de-obra assalariada temporária na agricultura, a partir de 1964, devemos nos ater à situação econômica vigente à época em que tal legislação começou a ser implementada. $\mathrm{O}$ período de 1964 a 1967 caratterizou-se por ser um periodo de baixos preços reais dos produtos agrícolas, de restriçōes de crédito e pela erradicação de cafeeiros em São Paulo, Paraná, Minas Gerais e Espirito Santo. Assim, a atividade agrícola sofria reduções de receitas (devido aos menores preços reais recebidos pelos produtos agrícolas) e elevaçōes de custos (devido à elevação dos custos financeiros). A implementação do Estatuto do Trabalhador Rural), ou a ameaça de sua implementação, elevava os custos de mão-de-obra, pois teria de ser pago o salário mínimo, o descanso remunerado, férias e indenização em caso de dispensa. Tal fato só deteriorou um ambiente depressivo, estimulando a dispensa de trabalhadores rurais, dado que a substituição de cafeeiros por outras ativiades, principalmente a pecuária, tornava grande parte da māo-de-obra ociosa, pois essas novas atividades demandavam menos mão-de-obra que o café (Veja PANAGIDES (1969, p. 46). Essa mão-de-obra residente dispensada constituiu, uma massa de trabalhadores ociosos, que puderam ser contratados como mão-deobra assalariada temporária.

A importância do Estatuto do Trabalhador Rural (ETR) como uma das causas da ampliação de volantes na agricultura brasileira era uma opinião unânime de patrōes, agrônomos e até de alguns sindicalistas rurais em São Paulo em 1968 (conforme constatamos no artigo COOPERCOTIA (1968), que expressa a opinião de indivíduos distintos presenciando o mesmo fenômeno. Além disso, dos dados de SILVA e GASQUES (1982, p. 90), constatamos que os trabalhadores rurais residentes em São Paulo diminuíram de 1.727 mil em março de 1964 para 1.036 mil em março de 1978, sendo que, no mesmo período, os trabalhadores não residentes (constituídos na maior parte de volantes) passaram de 324 mil para 454 mil, respectivamente. Até abril de 1975 , o número de trabalhadores residentes continou a diminuir. Tais dados confirmam a importância do ETR (e da legislação trabalhista ru-

res rurais e das ligas camponesas, que suplantaram o poder dos fazendeiros nas discussర̃es sobre essa legislaçắo no Congresso. O ETR năo foi uma pressăo dos fazendeiros, mas sim uma imposiçăo sobre a majoria e um consentimento para os que já substitulam colonos por assalariados. 
ral que Ihe substituiu) na aceleração da transformação do trabalhador residente em volante.

Pode haver dúvidas sobre a efetividade, no período inicial de vigência, da aplicação da legislação trabalhista rural. Assim sendo, realizamos abaixo uma avaliação da implementação dessa legislação em São Paulo no período inicial de sua vigência, sendo que a restriçāo à análise do caso paulista deve-se à falta de dados para os outros estados brasileiros.

Com relaçãơ a São Paulo, concluímos que a legislação trabalhista rural, no periodo inicial de sua vigência, elevou os salários agrícolas reais e possibilitou a uma parcela significativa dos trabalhadores agrlcolas auterir os outros beneflcios estabelecidos, como o domingo remunerado, as férias remuneradas e a indenização por tempo de serviço. A tais conclusões somos levados a partir do exame dos seguintes fatos:

a) comparando o salário mensal do diarista residente (WMDR) com o salário mínimo (WMIN) em São Paulo constatamos que a razão deles teve a seguinte evolução:

\section{IABELA 1 - RAZÃO ENTRE O SALÁRIO MENSAL DO DIARISTA RESIDENTE (WMDR) E O SALÁRIO MÍNIMO (WMIN) EM SÃO PAULO DE 1960 A 1969}

\begin{tabular}{cccccc}
\hline ano & WMDR/WMIN & ano & WMDR/WMIN & ano & WMDR/WMIN \\
\hline 1960 & 0,50 & 1964 & 0,78 & 1967 & 0,82 \\
1961 & 0,45 & 1965 & 0,89 & 1968 & 0,84 \\
1962 & 0,54 & 1966 & 0,82 & 1969 & 0,82 \\
1963 & 0,58 & & & & \\
\hline
\end{tabular}

FONTE: IEA (1972, p. 119).

O salto observado na razão WMDR/WMIN em 1964 e em 1965 e, em grande parte, atribuído à entrada em vigência do ETR. Como diz o texto do IEA (1972, p.118): 
“O maior nível observado nos salários agrícolas, a partir de 1964, decorre, em grande parte, da extensão das leis trabalhistas aos trabalhadores do campo e ao maior empenho em defesa dos seus direitos..."

Devemos ressaltar que, no cálculo do salário do diarista residente, não se incluem as remunerações em espécie referentes à moradia e alimentos cedidos pelos patrōes, sendo que o texto do IEA (1972, p.120) acredita que, grosso modo, sendo o salário agrícola monetário $80 \%$ do salário mínimo, a inclusão dos ganhos não monetários (moradia e alimentos cedidos) totalizam um salário agrícolà equivalente ao salário mínimo monetário.

b) Podemos considerar que os benefícios como domingo remunerado, férias remuneradas e indenização por tempo de serviço são auferidos por trabalhadores com carteira assinada. Para 1962, antes da promulgação da legislação trabalhista para o setor rural, é razoável supormos que parcela insignificante dos empregados agrícolas em São Paulo tivesse carteira de trabalho assinada pelo empregador. Segundo os dados das PNADs, em 1972, 23,57\% dos empregados agrícolas em São Paulo tinham carteira assinada pelo empregador, em 1976 eram $32,82 \%$, em $198126,23 \%$ e em 1985 eram $44,36 \%$.

Os fatos ' $a$ ' e 'b' nos indicam que a legislação trabalhista rural em São Paulo foi rapidamente cumprida no referente ao pagamento do salário mínimo, e moderadamente cumprida nos outros direitos do empregado agrícola. Podemos, assim, concluir que tal legislação aumentou os custos de utilização dos colonos em relação a um número mínimo de trabalhadores assalariados permanentes suplementados por trabalhadores assalariados volantes.

Quando aos outros estados brasileiros não possuímos dados de pagamento de salários agrícolas no período de 1960 a 1968, e quanto às percentagens de empregados agrícolas com carteira de trabalho assinada pelo empregador em 1972 temos que, em Pernambuco, essa percentagem foi próxima à de São Paulo, sendo bem menores em Minas Gerais, Bahia e na média do Brasil (veja a tabela 2). Tal fato nos leva à conclusão de que os impactos da elevação dos custos da legislação trabalhista rural não foram similares em todos os estados brasileiros. 


\section{TABELA 2 - PERCENTAGENS DE EMPREGADOS AGRI- COLAS COM CARTEIRA ASSINADA PELOS EMPREGADORES}

\begin{tabular}{cccccc}
\hline ANO & SÃO PAULO & PERNAMBUCO & MINAS GERAIS & BAHIA & BRASIL \\
\hline 1972 & 23,57 & 20,72 & 4,39 & 3,54 & 3,19 \\
1981 & 26,23 & 27,82 & 8,33 & 5,75 & - \\
1985 & 44,36 & 24,97 & 13,71 & 10,44 & 17,25 \\
\hline
\end{tabular}

FONTE: PNADS

Na agricultura mineira, os trabalhos de MOURA (1980) e de LUCAS (1984) avaliam a importância da legislação trabalhista rural na aceleração do uso de mão-de-obra temporária.

MOURA (1980) analisa as modificaçōes nas relações de produção no Vale do Jequitinhonha, onde a especialização das fazendas na pecuária mista, substituindo o velho empreendimento agrícola-pastoril, estava expulsando o agregado e o parceiro, e condicionando os remanescentes a prestarem serviços na base de diárias na atividade principal. As legislaçōes sobre a terra e o trabalho rural (nesse último o ETR e a lei de 08/06/1973 que o substituiu) apenas ratificaram o processo que já vinha ocorrendo, acelerando-o. Diz MOURA (1980, p.158):

"O impacto da legislação atual sobre a terra e o trabalho rural $(1963,1964,1973)$ ratifica, legalmente, um discurso alternativo e programa novos padrōes de relaçōes de trabalho entre fazendeiro e camponês, mas estes códigos, dando novo curso às açōes legais, reforçam a tendência à expulsâo, num esforço de suprimir a implementação do novo perfil de relaçōes ..." (grifo nosso)

LUCAS (1984, p.29), depois de analisar a evolução da legislação trabalhista no campo e sua importância como fator de expulsão do trabalhador das fazendas (como apregoa o discurso patronal), conclui que:

"Deve-se, contudo, explicitar que as informaçōes dispontveis não permitem descartar totalmente aquela proposição. Podese supor que, principalmente nas áreas mais estagnadas, onde é baixa a rentabilidade $e$ alto o percentual da remuneração da mão-de-obra sobre as despesas totais dos estabelecimentos, a legislação seja urn fator que, associado a outros, contribua para a 
aceleração dos movimentos migratórios. O que se torna diffcil admitir é que, no conjunto do Estado, ela exerça sobre o êxodo rural uma influência sequer próxima daquela apregoada no discurso patronal."

Outro fato a acelerar a substituição dos colonos por trabalhadores assalariados temporários e permanentes foi o avanço técnico na agricultura brasileira. A política de modernização, via concessão de créditos subsidiados à compra dos insumos modernos, alterou o "ceteris paribus" dos fazendeiros, reduzindo a relação entre os preços desses insumos e o de trabalho, de modo a conduzir os fazendeiros a adquirirem mais insumos modernos.

SILVA (1981) ressaltou que esse avanço técnico foi feito de maneira que aumentou a descontinuidade no uso de mão-de-obra na agricultura. $\mathrm{O}$ aumento de produtividade eleva o uso de mão-de-obra na época da colheita, e a mecanização e o uso de outros insumos modernos diminui o uso de mão-de-obra nas etapas de plantio e tratos culturais. Desse modo, tornou-se mais lucrativo, porque implica menores custos o uso de um número mínimo de trabalhadores assalariados permanentes suplementados pelos trabalhadores assalariados temporários nos momentos de demanda de mão-de-obra acima da capacidade de ser oferecida pelos primeiros, do que o uso de colonos que ficariam pouco utilizados em certas épocas do ano, mas recebendo seus salários.

O excedente de mão-de-obra das propriedades, gerados pela mudança de atividades (substituição de café por pecuária) e pela modernização, foi expulso das fazendas (e, aqui, o medo gerado pelo ETR superou o interesse político de manter agregados ociosos nas fazendas), gerando um mercado de trabalho rural onde pôde-se contratar trabalhadores volantes.

\section{4 - CONCLUSÃO}

Da exposição acima, podemos concluir que fenômenos institucionais (representados pela legislação trabalhista rural), a mudança de culturas e o avanço tecnológico na agricultura tornaram os custos de utilização de colonos mais elevados em relação ao uso de um número mínimo de trabalhadores permanentes suplementados por trabalhadores temporários (esse é o lado da demanda por formas de mão-de- 
obra). O uso dessa combinação pelos fazendeiros (que implica menores custos e, portanto, em maiores lucros) só foi possivel devido à existência de uma massa de trabalhadores aptos ao serviço rural, e que se constituiu dos expulsos das fazendas (pela legislação trabalhista, pela modernização e pelas erradicaçōes de cafeeiros) e de seus descendentes (esse é o lado da oferta de formas de mão-de-obra).

Observe-se que os fazendeiros, considerados como firmas, atuam de maneira racional ao substituirem os colonos por assalariados, quando os seus "ceteris paribus" se modificam de modo a alterar a relação de custos entre aquelas formas de uso de mão-de-obra. A decisão de substituir as formas de rnão-de-obra é do fazendeiro, mas essa é influenciada pela política econômica e pela agroindústria modificando o "ceteris paribus" sobre o qual os fazendeiros tomam suas decisões.

\section{5 - BIBLIOGRAFIA}

BACHA, Carlos J.C. Evolução Recente da Cafeicultura Mineira: Determinantes e Impactos. São Paulo, IPE/FEA/USP, São Paulo, 1988. (Tese dout. econ.), USP.

BRANT, Vinícius C. "Do Colono ao Bóia-Fria: Transformações na Agricultura e Constituição do Mercado de Trabalho na Alta Sorocabana de Assis" in Estudos Cebrap 19, jan-fev-mar 1977, p. 37-91.

CACCIAMALI, M.C. e AGUIRRE, B.M.B. Avaliação do Funcionamento de Cooperativas de Trabalhadores Agrícolas. Relatório de Pesquisa, Ministério do Trabalho/Fundação Instituto de Pesquisas Econômicas, setembro de 1984.

COOPERCOTIA. "A Nova Face da Agricultura", Coopercotia, outubro de 1968, p. 14-21.

D'INCAO E MELLO, M.C. (1976) O “Bóia-Fria”: Acumulação e Miséria. Petrópolis, 4" Edição, Editora Vozes Ltda, 1976.

GASQUES, J.G., VALENTINI, R.; MARTIN, M.A.; JUNQUEIRA, A.A.B. "A Força de Trabalho Volante na Agricultura Paulista" in Agricultura em São Paulo. Ano XXIV, Tomo I e II, 1977, p. 83 a 94.

GONZALES, Elbio N. e BASTOS, Maria I. "O Trabalho Volante na Agricultura Brasileira" in PINSKY, J. (org.) Capital e Trabalho no 
Campo. São Paulo, Editora HUCITEC, 1979, p. 25-47.

IEA - SÃO PAULO. Secretaria da Agricultura. Instituto de Economia Agrícola. Desenvolvimento da Agricultura Paulista. São Paulo, 1972.

LUCAS, Luiz C.G. "L.egislação Trabalhista e Êxodo Rural em Minas" in Fundação JP. 14(1/2): 21-59, jan.-fev. 1984, Belo Horizonte.

MOURA, Margarida M. "Ações Judiciais e Tensões Sociais no Vale do Jequitinhonha" in VI Reunião Nacional sobre Mão-de-Obra Volante na Agricultura. Botucatu, FCA, 1980, p. 147-161.

PAIVA, R.M.; SCHATTAN, S.; e FREITAS, C.F.T. Setor Agrícola do Brasil: Comportamento Econômico, Problemas e Possibilidades. Editora Forense-Universitária e Editora da Universidade de São Paulo, 1976.

PANAGIDES, S. "Erradicação do Café e Diversificação da Agricultura Brasileira" in Revista Brasileira de Economia 23(1):p. 41-71, jan.março 1969.

SILVA, J.G. Progresso Técnico e Relações de Trabalho na Agricultura. São Paulo, Hucitec. 1981.

SILVA, J.C. e GASGUES, J.G. (1982) "Diagnóstico Inicial do Volante em São Paulo" in A Mão-de-Obra Volante na Agricultura. Botucatu, FCA, Departamento de Economia Rural, 1982, p. 85-125.

SILVA, J.G. e RODRIGUES, V.L.G.S. "A Problemática do "Bóia-Fria": uma Revisão Bibliográfica" in A Mão-de-Obra Volante na Agricultura. Botucatu, Departamento de Economia Rural, FCA, 1982, p. 56-76.

STOLCKE, Verena. Cafeicultura - Homens, Mulheres e Capital (1850-1980). São Paulo, Editora Brasiliense, 1986. 